\title{
1968 Y DESPUÉS: LECCIONES DE UN CICLO HISTÓRICO
}

\section{AND AFTER: LESSONS OF A HISTORICAL CYCLE}

Jaime Pastor Verdú

UNED

\section{RESUMEN}

1968 marca un antes y un después en la historia contemporánea con un impacto global innegable, pese a que las expectativas de cambio radical que generó no llegaron a cumplirse. Sin embargo, la grieta que abrió en el consenso global dominante permitió, a pesar de la contraofensiva neoliberal, el desarrollo de nuevas oleadas de protestas: las protagonizadas por los «nuevos movimientos sociales», por el movimiento «antiglobalización» y, en el caso español, por el 15M. En todas ellas cabe encontrar similitudes pero también diferencias relevantes respecto al significado de aquel Acontecimiento global.

Palabras Clave: consenso, movimientos sociales, ciclos de protesta, Acontecimiento.

\section{ABSTRACT}

1968 stands as a crucial milestone in contemporary history bestowed as it was by an undeniable global impact even though the expectations of radical change that it fostered were not accomplished. Nevertheless the cleavage that 1968 created within the dominant global consensus, albeit the counterattack of neoliberalism, enabled the emergence of new waves of protest as those carries out by the «new social movements», the «antiglobalization» movement or the M-15 movement in the case of Spain. Among all these movements one might find similarities as well as significant differences concerning the meaning of that global milestone.

Keywords: consensus, social movements, cycles of protest, Event.

\section{SUMARIO}

1.- Introducción. 2.- Un Acontecimiento global. 3.- «Nuevos movimientos sociales» vs. neoliberalismo. 4.- «Otro mundo es posible». 5.- La nueva ola de indignación de 2011 y el 68. 6.- Bibliografía. 


\section{Introducción}

«La globalización neoliberal no es una herencia de Mayo del 68, sino de nuestra derrota», Pierre Rousset (Entrevista, Gladys Martínez, elsaltodiario.com, 22/07/2018)

Cuando en una carta dirigida a Karl y Gertrud Jaspers el 26 de junio de 1968 Hannah Arendt pronosticaba que «los niños del siglo XXI aprenderán del año 1968 igual que nosotros aprendimos de 1848», hacía sin duda un pronóstico arriesgado que no podía ocultar su entusiasmo por aquellas jornadas. Hoy, 50 años después de aquel Acontecimiento global, no parece que esa profecía se haya llegado a cumplir en las aulas, pero no por ello la polémica sobre el lugar en la historia y el significado de «los años 68» ha dejado de estar presente tanto en el ámbito académico como en el más político o cultural.

\section{Un Acontecimiento global}

En efecto, como ya recordábamos en el número 12 de esta misma revista (2008), el punto de inflexión que marcaron aquellas jornadas en la historia posterior a la Segunda Guerra Mundial es innegable y así ha sido reconocido en la mayoría de los estudios dedicados a esos eventos. Significaron un cuestionamiento de las bases del «consenso» de posguerra en las sociedades del Norte, tanto en el Oeste (Francia, principalmente) como en el Este (Checoslovaquia), sacudidas a su vez por las revoluciones y revueltas que se extendían en el Sur (Vietnam, Pakistán, México...). Fueron, por tanto, un Acontecimiento en cuanto que constituyeron un «momento crítico» que hizo posible que la doxa y la percepción del mundo convencional fueran puestas en cuestión en proporciones inéditas (Gobille, 2008). En ese sentido, más allá de sus especificidades nacionales, formaron parte de un «Gran Rechazo» compartido frente a lo «realmente existente», tal como lo calificaron Maurice Blanchot o Herbert Marcuse.

Mostraron una dimensión antiimperialista, anticapitalista y antiautoritaria innegable, incluyendo también en esa impugnación la crítica a los grandes partidos de la izquierda, tanto a la socialdemocracia como, aunque de forma más desigual, a los partidos comunistas -con mayor razón a aquéllos que estaban en el poder-, por considerar que se habían integrado en el sistema y que se habían comportado como «partidos de orden» durante esas jornadas. Fue ese diagnóstico el que condujo a la búsqueda de una política alternativa que llevó a la proliferación de nuevas organizaciones con referentes ideológicos distintos-maoístas, trotskistas, consejistas o libertarios- que apostaron por proyectos revolucionarios que 
creían posibles en aquel entonces, como también llegaron a temerlo sus enemigos (Boltanski y Chiapello, 2002: 243). Porque, aunque aquellas jornadas no llegaron a transformarse en revoluciones, sí fueron vividas como tales por muchas de las personas que en ellas participaron, como demuestra la larga relación de testimonios publicada desde entonces. Muchos de ellos, especialmente en Francia, buscaban recuperar la memoria colectiva de procesos revolucionarios anteriores, desde la Revolución francesa hasta la Comuna de París, como recordaba una de las activistas: «¡En el 68 tuve la impresión de vivir lo que se había vivido en el 89, durante la Comuna, y también en 1830 y 1848!» (Daum, 2018: 327). Fue en ese sentido una «revolución de la percepción» basada en la constitución, temporal pero efectiva, de una «comunidad emocional» (Bantigny, 2018: 224) que enlazaba con momentos de efervescencia colectiva vividos en el pasado.

Con todo, la «brecha» abierta y el «subsuelo» creado, en afortunadas metáforas de Edgar Morin, permitieron crear las condiciones para una nueva etapa en la historia de los movimientos sociales que a su vez iría chocando con las respuestas que desde arriba fueron poniéndose en pie para frenar $\circ / y$ reconducir la dinámica potencialmente antisistémica iniciada entonces. Ésta se empezaría a cerrar a partir del golpe de estado de Pinochet en Chile en septiembre de 1973 y de la derrota de la Revolución portuguesa en noviembre de 1975 en el marco de un cambio de ciclo de la economía capitalista (Husson, 2008). Informes como el de la Comisión Trilateral de 1975, el cual alertaba frente a la «sobrecarga de demandas democráticas» y a la «crisis de gobernabilidad» que se estaba extendiendo a muchos países por el "efecto 68», contribuirían al ascenso del neoliberalismo como «nueva razón del mundo» (Dardot y Laval, 2013). Ésta se mostró dispuesta a reemplazar al «sentido común» hegemónico hasta el 68 en Occidente, basado en el compromiso fordistakeynesiano del bienestar, para ir expandiéndose a otras partes del mundo. Mientras tanto, en el Este la ocupación por el Pacto de Varsovia de Checoslovaquia en agosto de 1968 marcaría el inicio de la progresiva crisis del bloque soviético, agravada por la competencia desigual y creciente -especialmente en el plano militar-con el bloque occidental hegemonizado por EE UU.

En cambio, en el llamado Tercer Mundo la guerra de Vietnam se convertiría en una gran derrota para el imperialismo norteamericano y en un estímulo para los movimientos guerrilleros en otras regiones del mundo, particularmente en América Latina. El triunfo de la Revolución sandinista en 1979 sería el punto más alto al que llegó ese ciclo, precedido no obstante por grandes derrotas en el Cono Sur de esa región que seguirían la estela de la dictadura militar chilena. 


\section{3. "Nuevos movimientos sociales" vs. neoliberalismo}

Centrándonos ahora en el contexto geopolítico occidental, lo más relevante fue la irrupción de los denominados «nuevos movimientos sociales», especialmente el feminista, el ecologista y el pacifista radical, al igual que otros dirigidos a cuestionar las distintas instituciones de control social, el espacio urbano 0 , simplemente, la vida cotidiana, pese a que el 68 apenas tuvo alguna de esas características' ${ }^{1}$. ¿Por qué fue así? Porque, pese a sus limitaciones, sí se introdujo lo que Boltanski y Chiapello (2002) denominaron «crítica artista», o sea, la crítica del capitalismo como fuente de desencanto y de inautenticidad y como fuente de opresión, lo cual permitiría trasladarla luego en relación al patriarcado, al dominio sobre la naturaleza o a la creciente nuclearización y militarización del mundo.

Pero, además, esa «crítica artista» también iba unida a la búsqueda de la «autonomía» frente a la «heteronomía» en el trabajo y no fue casual que después del 68 resucitaran los debates sobre la autogestión que ya tenían su referente crítico -puesto que se enfrentaban con el despotismo burocrático- en las experiencias que se estaban viviendo en Yugoslavia. Esa vocación de «autonomía» estaba ligada además, como también analizaron Boltanski y Chiapello, a la «crítica social», a la denuncia del capitalismo como fuente de miseria y de desigualdades pero también de oportunismo y de egoísmo y, por tanto, a la exigencia de igualdad social. Fue esa asociación entre ambas críticas la que tuvo su reflejo simbólico en luchas como la de los trabajadores de LIP o en el movimiento de los consejos de trabajadores en Italia, expresando así una aspiración común a ir más allá del paradigma del Estado del bienestar e incluso a «hacer la revolución». En resumen, «las críticas de la alienación y de la explotación son en muchos sentidos inseparables en mayo-junio de 1968» (Gobille, 2018).

En cambio, el gran éxito del «nuevo espíritu del capitalismo» estaría en ir disociándolas desde mediados de los años 70 en el marco de la creciente hegemonía de la «contrarrevolución preventiva» neoliberal que ya, con el colapso del bloque soviético, tendría un alcance global. Un proyecto que no se habría llevado a término sin la colaboración de la mayoría de la izquierda socialdemócrata, como en Alemania por ejemplo, y comunista, como en Italia, así como de las grandes organizaciones sindicales.

Esa creciente separación entre ambas críticas facilitó la tarea de desestructuración del mundo del trabajo («la movilidad del explotador tiene como contrapartida la flexibilidad del explotado») y, a la vez, limitó el potencial anticapitalista de esos «nuevos movimientos

1 Como recordaba Daniel Bensaïd a propósito del feminismo: «Reconocemos, hoy en día, la composición exclusivamente masculina de las tribunas de oradores y fuertemente masculinizada de los cortejos. El nuevo movimiento feminista apareció más tarde, con la ofrenda floral el 20 de agosto de 1970 en memoria de la "mujer del soldado desconocido"» (Bensaïd, 2008: 23-24). 
sociales» a lo largo de los decenios siguientes. Pero no por ello éstos dejaron de introducir en la agenda política nuevos temas y nuevas líneas de fractura que siguen atravesando al conjunto de nuestras sociedades, emprendiendo ciclos de luchas que tuvieron su «cresta de la ola» y su relativa fusión en las movilizaciones de la primera mitad del decenio de los 80 a escala euro-occidental contra los «euromisiles» y el «exterminismo» como tendencia que acompañaba a la competencia intersistémica existente entonces. En el caso español tuvieron su especificidad en el potente movimiento antiOTAN que se desarrolló desde enero de 1981 hasta el referéndum celebrado en marzo de 1986, con la victoria final del Sí a la OTAN.

Los impactos de esos movimientos fueron notables en el plano político-cultural, pero no llegaron a satisfacer las expectativas de cambio de paradigma que generaron en torno a una «nueva política» y una «nueva forma de hacerla». Se pudo comprobar esto con la evolución sufrida por la expresión política con mayor anclaje social dentro del eco-pacifismo, el Partido Verde alemán, mediante el triunfo final de los «realistas» no sólo frente a los «fundamentalistas» sino también contra las corrientes alternativas que, partiendo de la centralidad de los movimientos sociales, no renunciaban por ello a intervenir políticamente en el terreno electoral e institucional (Wolf, 2007a y b).

Esos movimientos se convirtieron, no obstante, en actores políticos, sociales y culturales, en muy diversas partes del mundo, adquiriendo rasgos a la vez comunes y distintos en función tanto de su propia diversidad como de su mayor o menor articulación con otras líneas de fractura que atraviesan a nuestras sociedades, ya sea la clase, la etnia, la nación, el color de la piel o la religión. Sin embargo, una parte de ellos conoció un proceso de «oenegeización» -o de adaptación como meros grupos de presión a dinámicas de «contienda política contenida» (McAdam, Tarrow y Tilly, 2005: 8-10)- que ha ido debilitando su potencial de protesta antisistémica en favor de una mayor colaboración con las instituciones y de la cogestión de proyectos que, en la mayoría de los casos, se limitaron a paliar los efectos más negativos del «modelo» neoliberal.

\section{4. "Otro mundo es posible»}

Llegaría luego el movimiento «antiglobalización», ya en el contexto de finales de la década de los 90 del pasado siglo, si bien se puede considerar el levantamiento neozapatista de enero de 1994 como pionero de la denuncia de la globalización neoliberal tras la descomposición del bloque del autodenominado «socialismo real» y la progresiva reinserción de China en el mercado capitalista. De su evolución posterior se podrían destacar los siguientes rasgos: la tendencia a la homogeneización de las políticas neoliberales a escala global abrió 
nuevas «avenidas de protesta» transnacionales a través de las cuales se fueron manifestando una diversidad de redes y organizaciones sociales críticas; se fue conformando así un «movimiento de movimientos» que asumió el reto de ligar los problemas globales con las realidades locales y el malestar creciente de «los y las de abajo», con el fin de ir construyendo una amplia mayoría social a favor de una «globalización alternativa»; a través de los sucesivos Foros Sociales Mundiales fueron alcanzando un amplio consenso de trabajo en común en torno a demandas que cuestionaban la lógica mercantilizadora de cualquier bien humano y terrenal; asimismo, apostaron por formas de desobediencia social que contribuyeron a deslegitimar las políticas neoliberales y a las instituciones que las propugnan.

Ese movimiento tomaba el relevo de los «nuevos» movimientos sociales y enlazaba con el «espíritu del 68» reformulando la «crítica social» a un capitalismo financiarizado, integrando a su vez la «crítica artista» procedente del ecologismo y el feminismo, pero también la de los pueblos indígenas y su denuncia del «lado oscuro de la Modernidad», la «colonialidad del poder», tal como lo definió Aníbal Quijano, y la consiguiente clasificación racial de los seres humanos. El contexto era sin embargo muy distinto, sin expectativas revolucionarias en el horizonte ante el triunfalismo que el neoliberalismo mostraba tras la caída de la URSS. Con todo, quizás el nexo de unión más relevante con aquel Acontecimiento estuviera en el retorno del anticapitalismo como rechazo del discurso del TINA («There is No Alternative») y la apuesta por construir alternativas frente al mismo mediante el eslogan «Otro mundo es posible».

Un rasgo singular de este «movimiento de movimientos» estuvo en su estructuración organizativa prácticamente global, superando tanto el «tercermundismo» del 68 como el eurocentrismo que caracterizó a muchos «nuevos» movimientos sociales. A todo esto se sumaba una composición intergeneracional más acusada, dentro de la cual era fácil encontrar, incluso en sus grupos motores, a una parte de los y las activistas del 68. Empero, el anclaje nacional y local de la mayoría de las redes de estos movimientos no llegó a ser lo suficientemente fuerte para resistir el reflujo posterior al desencadenamiento de la guerra de Iraq, pese al éxito alcanzado con la movilización global del 15 de febrero de 2003.

\section{La nueva ola de indignación de 2011 y el 68}

Muy distinto es el caso del ciclo de protestas que se produjeron a partir de la «primavera árabe» a inicios de 2011 y que llegó a extenderse a otros países, teniendo una de sus expresiones más relevantes en el «movimiento $15 \mathrm{M}$ » español. El contexto era ya de una crisis abierta de lo que se había presentado como «la globalización feliz» y, en nuestro caso, 
de un ya menguante Estado de bienestar, a raíz de la crisis financiera y sistémica que había estallado en septiembre de 2008 en EE UU. La frustración de expectativas de mejora y de movilidad social ascendente daba un carácter marcadamente defensivo a las protestas, lo cual las distinguía claramente de lo vivido en el 68 e incluso del ciclo en el que se desarrollaron los «nuevos» movimientos sociales (Pastor, 2012).

Estas diferencias fueron patentes en el caso español, pero no por ello se pudo dejar de observar algunas similitudes con el 68: en el protagonismo de la juventud -en este caso, principalmente en la recién salida de la Universidad-, en la ocupación de la calle -en este caso, de las plazas como espacios simbólicos de la protesta-, en las prácticas asamblearias y de «toma de la palabra», con una enorme creatividad en los mensajes y eslóganes; en el rechazo a los partidos tradicionales y la búsqueda de otra política y otra forma de hacerla. Y, sobre todo, en el entusiasmo y en la efervescencia colectiva, características de todo Acontecimiento, que se vivió en las plazas de Madrid y en un creciente número de ciudades y pueblos durante el nuevo ciclo de luchas que se abrió a partir de entonces y concluyó a mediados de 2013.

Algunas diferencias eran innegables también respecto al 68: el escaso papel de las organizaciones políticas, incluidas las radicales, en ese movimiento; la ausencia de interés en la búsqueda de confluencia con una clase obrera -y sus sindicatos- que aparecía ya desestructurada y debilitada política y sindicalmente; la opción por una desobediencia civil no violenta y ejercida de forma colectiva, a una escala masiva inédita hasta entonces; la reivindicación de una «democracia real» como idea fuerza, resignificándola frente a la convencional - «lo llaman democracia y no lo es»- y prefigurándola con la deliberación directa en las plazas y con el apoyo de las nuevas tecnologías de la información y de la comunicación; pero también un discurso de rechazo a los ataques a servicios públicos y derechos sociales - «Se vende Estado de bienestar»- y a la corrupción estructural -«no somos antisistema, el sistema es antinosotros». Empero, el eslogan con que comenzó el 15M-«No somos mercancía de políticos y banqueros»- y otros posteriores - «No es una crisis, es una estafa»-sí contenían un mensaje antineoliberal y anticorrupción que, en cierto modo, buscaba una alternativa basada en la defensa de los «bienes comunes» como un eje fundamental frente a las nuevas formas de acumulación por desposesión capitalista. Otro rasgo diferente fundamental era el peso creciente que, pese a las tensiones iniciales, va conquistando el feminismo en el conjunto de redes e iniciativas «hijas del $15 \mathrm{M} »$, el cual le permitiría posteriormente conectar a su vez con una nueva generación que tuvo en el 8 de marzo de 2018 su máxima expresión hasta ahora.

Así, con sus diferencias y sus similitudes, el ciclo abierto por el 15M significó una repolitización de la sociedad española, llegando a dotarse de una composición social in- 
tergeneracional que le permitió incorporar a una parte de quienes se habían socializado en el ciclo abierto por el 68 y, más en concreto, en las luchas que se desarrollaron bajo el tardofranquismo. En ese sentido, quizás el 15M tuvo que ver más con la re-visión de la «Transición» española y la recuperación de la ilusión en ir más allá del «desencanto» que aquella provocó en sus minorías activas que con el 68 , dadas además las particularidades que éste tuvo aquí bajo las condiciones de una dictadura que todavía no había entrado en crisis abierta.

Así, del sucinto análisis del recorrido vivido desde 1968 hasta el momento actual, la principal lección a extraer debería ser reconocer, con Arendt y Wallerstein, que pese a su derrota política aquel Acontecimiento marcó un hito en la historia del siglo XX similar al que marcó 1848 en el siglo XIX. Porque significó, como aquél, un antes y un después en la historia de los movimientos sociales y, además, permitió ir haciendo visibles nuevas esferas de conflicto en nuestras sociedades contemporáneas, como hemos podido comprobar en las sucesivas olas de movilización posteriores. También nos enseñó a comprender que la historia no es lineal sino llena de discontinuidades, demostrando una vez más que el potencial desestabilizador de las injusticias provoca resistencias y protestas que culminan periódicamente en explosiones de malestar en las que se produce una expansión del campo de lo posible, convirtiendo «lo extraordinario en cotidiano», en palabras de Henri Lefebvre. Por eso, frente al constante esfuerzo de las memorias oficiales por enterrar el 68 como una «pesadilla» que ha de pasar al olvido, seguiremos reivindicándolo como «el año en el que el mundo pudo cambiar de base». Porque son sus brasas y no sus cenizas, como reclamaba Daniel Bensaïd, y su «melancolía rebelde», como nos proponen Enzo Traverso o Michael Löwy (2017), su verdadero legado.

\section{6.- Bibliografía}

BANTIGNY, Ludivine (2018). De grands soirs en petits matins, París: Seuil.

BENSAïD, Daniel (2008). «Finales y consecuencias». En PASTOR, Jaime, ROMERO, Miguel y Manuel GARí (eds.) (2008). 1968. El mundo pudo cambiar de base, Madrid: Los Libros de la Catarata-Viento Sur, pp. 19-28.

Boltanski, Luc y Eve Chiapello (2002). El nuevo espíritu del capitalismo, Madrid: Akal. DARDOT, Pierre y Christian LAVAL (2013). La nueva razón del mundo, Barcelona: Gedisa. DAUM, Nicolás (2018). Mayo del 68: la palabra anónima, Madrid: Acuarela y Machado. 
GoBlLE, Boris (2008). «L'évènement Mai 68. Pour une histoire du temps court», Annales. Histoire, Sciences Sociales, 2, pp. 321-349.

(2018): «Explotación, alienación y división social del trabajo», Viento Sur, 17 de febrero. Accesible en www.vientosur.info/spip.php?article 13490

Husson, Michel (2008). «Debates sobre economía», Viento Sur, 06/08/2008.

LöWy, Michael (2017). «Melancolía de izquierda», Viento Sur, 24 de julio.

McAdam, Doug, Tarrow, Sidney y Charles Tilly (2005). Dinámica de la contienda política, Barcelona: Hacer.

PASTOR, Jaime (2008). «Mayo 68, de la revuelta estudiantil a la Huelga General. Su impacto en la sociedad francesa y en el mundo», Dossiers feministes, 12, pp. 31-47. (2012): «El movimiento 15M y la política extraparlamentaria». En C. Colino y R. Cotarelo (eds.), España en crisis, València: Tirant lo blanch, pp. 358-381.

Wolf, Frieder Otto (2007a). «Cayendo por la pendiente deslizante de la democracia parlamentaria, I», Viento Sur, 90, pp. 9-23.

(2007b): «Cayendo por la pendiente deslizante de la democracia parlamentaria, Il», Viento Sur, 91, pp. 5-18. 